The Electrical Capacity of Gold-leaf Electroscopes

This content has been downloaded from IOPscience. Please scroll down to see the full text. 1915 Proc. Phys. Soc. London 28162

(http://iopscience.iop.org/1478-7814/28/1/318)

View the table of contents for this issue, or go to the journal homepage for more

Download details:

IP Address: 128.192.114.19

This content was downloaded on 29/08/2015 at 14:27

Please note that terms and conditions apply. 
XVII. The Electrical Capacity of Gold-leat Electroscopes. By T. BARratt, D.Sc., A.R.C.S.

Received March $20,1916$.

\section{INTroduction and Historical.}

T'uF modern gold-leaf electroscope has for some considerahte time been employed by workers in radioactivity as an instrument of precision comparable with that of other insirn. ments used in electrical measurements. Many worke's in other branches of physics, however, still appear to regard the instrument as of merely historical interest. It is the 2 perience of the author that with the help of the gold-lenat electroscope measurement of potential can he made with an accuracy of, at any rate, 1 per cent. between, say, 50 and :301 volts, the limits depending on the particular instrument. 'T'h" gold-leaf electroscope possesses many advantages over the usual type of electrometer. The latter is exceedingly trouble. some to set up and to work, and requires very great care in maintaining satisfactory insulation. Its capacity is man! times that of the electroscope, which can, therefore, measure much smaller currents. [See Paper by (. W. C. Kave. Phr'. Soc. "Proc.," 2:3, p. 209, 1911.] In addition, the electroscop" is much cheaper, takes up very little space, is easily transported and can be used in any position.

Methods for the determination of the capacity of the goldleaf electroscope have been given by F. Haims* and by Lichtenecker.t In the measurement of such small capacitiethe usual commutator methods cannot be employed. Accurat" and well-insulated standard condensers of the same order of rapacity as that of the electroscope cannot be obtained; and. again, the capacity of any connecting wires, switches, \&c., are of the same order of magnitude as that of the leaf system itself. and are not known with any degree of accuracy. In order to overcome the latter difficulty, Harms st allowed drops of mercury, alcohol or water to fall from a charged capillary tube into an ionisation vessel connected with the electroscope. Obviously the method cannot be employed with an electro1903.

* "Phys. Zeit.," 5, p. 47, 1904; "Ann. d. Physik.," 10, p. 816, March.

†" Phys, Zeit.," p. 516, 1912.

\$ "Phys. Zeit.," 5, p. 47, 1904; “Ann. d. Physik.," 10, p. 816, March, 1903 
sepe not possessing such an ionisation vessel. In experimint often took 18 minutes to perform, and corrections had to be made for loss of potential during that time. It would also. apyrar that a further correction was necessary for electrical "moury produced by the fall of the drops of liquid from a great hright (over $100 \mathrm{~cm}$.). Lichtenecker* attached a sphere to the wretroscope by a long wire, and by measuring the capacity of the clectroscope, sphere and wire fol various lengths of the wire deduced the caparity of the electroscope alone. In both of these methods elaborate apparatus was necessary, and the indivirlual results differed in some cases by as much as 10 pel (rint.

The method that appears to be generally used in the laboratom is to charge the electroscope to a kirown potential, allow it to share its charge with a small sphere of a few cms. riameter, and deduce the capacity of the electroscope from thr observed drop of potential. Cinfortunately, however, the calparity of the electroscope when in contact with the splere is rolr different from its true capacity, and Hamst remarks that results differing by 25 per cent. will be obtained by this mothor. For example, the joint capacity of two spheres in contact. each of radius $a$, is not $2 a$, but $2 a \times \log 2+$ If the phores are of radii $a$ and $b$, and if $b / a$ is large, the capacity of the smaller sphere is not $a, b u t \frac{a^{2}}{b} \cdot \frac{\pi^{2}}{6}$.

It is impossible, however, to obtain a similar formula for the combined capacity of a sphere and a conductor of such a shaje as the rod and leaf of a gold-leaf electroscope.

\section{Apparatus and Method of Experiment.}

Preliminary experiments showed that the use of a parallel. plate air condenser in place of a sphere overcame this difficulty. There is nothing new in the method except in some of its details. For example, contact is made between condenser and electroscope, not once, but if necessary several times, the electroscope being earthed each time after contact. A long thin copper wire (gauge 30 ) is attached to the insulated plate of the condenser, which consists of plate glass covered with thin tinfoil (the two sheets of tinfoil facing each other), and

\footnotetext{
* "Phys. Zeit.," p. 516, 1912, 1903.

$\dagger$ "P Phys. Zeit.,", 5, p. 47, 1904 ; “Ann. d. Physik.," 10, p. 816, March,

¥.J. J. Thomson, "Elemts. of Elec. and Mag.," 3rd edition, p. 181.
} 
insulated by three pieces of sulphur, whose thickness is accurately measured by a micrometer screw gauge. If the sulphur be scraped by a sharp penknife its insulating powers are almost perfect. The condenser is surrounded by a guard ring, so that its capacity is known with accuracy. In the present series of experiments a second condenser (without a guard ring) was used, its capacity having been first carefully compared with that of the guard-ring condenser. The capacity included that of the attached copper wire. It was found that the reading of the leaf of the electroscope was very nearly the same when joined to the condenser by the connecting wire as when the Jatter was disconnected and earthed. The fact that nearly all the lines of force of the condenser are crowded between the plates no doubt accounts for this.

The necessury small correction for the difference between the capacity of the electroscope as obtained by the above method and its true capacity (i.e., its capacity when the usual conductors in the vicinity of the leaf system are all earthed) is easily obtained. It is found by experiment that the potential, as indicated by the position of the leaf, is slightly reduced when the attached wire from the condenser is disconnected and earthed. The percentage reduction is found to be the same. within errors of experiment, for all values of the potential. It varies slightly for different electroscopes, but is never more than about 2 per cent. If the potential is reduced from $V$ to $V^{\prime}$ on removing and earthing the wire, then, as the charge on the leaf system is unaltered, the capacity is changed from $C^{\prime}$ to $C^{\prime}$, where $C^{\prime} V^{\prime}=C V$, or true capacity $C^{\prime}=C V / V^{\prime}$.

For example, in the case of the electroscope examined in Section 1II. (i.), $V=300, V^{\prime}=294, C=7 \cdot 13$.

Hence, true capacity $=390 \times 7 \cdot 13 / 294=7 \cdot 27 \mathrm{~cm}$.

The electroscope and reading microscope were firmly secured to a rigid bench. I vernier attached to the microscope, and reading to one-twentieth of a millimeter, moved along a horizontal scale, and the reading of the leaf was obtained at potentials of $20,40,60, \ldots .300$ volts, as given by a battery of small accumulators, standardised by a voltmeter. A curve was then diawn connecting potential of leaf and reading of microscope scale. Such a curve is given in Fig. 1.

The battery, which has proved exceedingly satisfactory. was made in the laboratory at a very small cost. The cells were arranged in rows of $10^{\circ}$, and could all be charged together by about 1.2 or $1: 3$ accumulators of the usual laboratory type. 
The electroscope and condenser were connected and charged by means of an ebonite rod to a known potential, given by the reading on the scale and by reference to the curve. The wire from the condenser was disconnected from the electroscope with the help of a rod of sulphur, and the electroscope earthed by means of a copper wire soldered to the gas pipes. The condenser was again connected to the electroscope, disconnected, and the electroscope earthed. This process of alternate earthing of the electroscope and sharing the charge of the condenser was repeated as many times as necessary, and the capacity of the electroscope deduced. It is to be observed that the connecting wire does not form a part of the capacity to be measured, but is included in that of the condenser. The experiment takes only a few seconds, so that no correction is necessary for loss of charge.

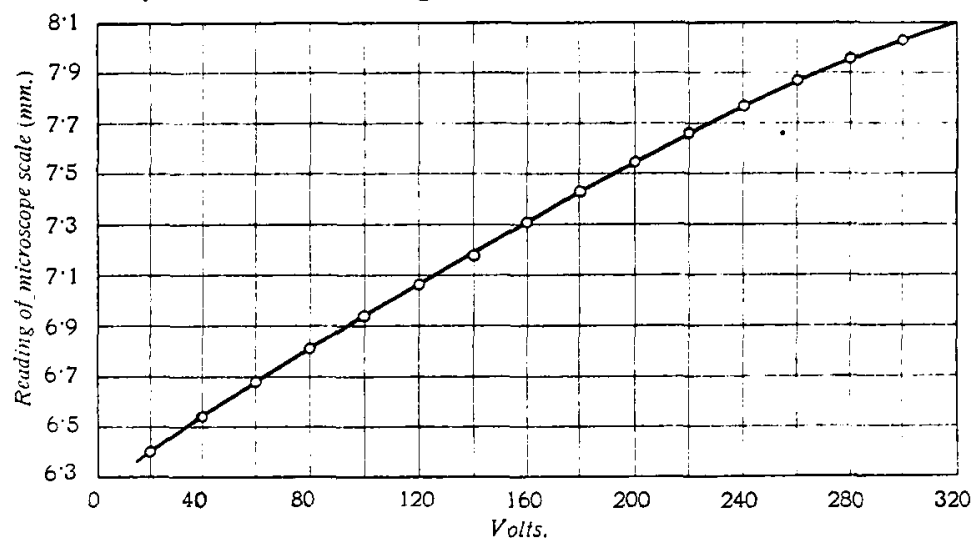

Fir. 1.-Curve Connecting Potental of Leaf axp Readisi on Microscofe Scale.

If $\mathrm{V}$ is the original potential of the condenser and $C$ its capacity, $v_{n}$ the final potential of the system after $n$ alternate earthings and re-chargings as above, and $c$ the required capacity of the electroscope, it can easily be deduced that

$o r$

$$
v_{n}=\left(\frac{C}{C+c}\right)^{n} \cdot V
$$

$$
\log (C+c)=\log C+\frac{1}{n}\left(\log V-\log v_{n}\right) \text {. }
$$

III. Determinations of Capacity.

1. Cubical Lend Electroscope.-The edge of the electroscope was of length $20 \mathrm{~cm}$. A central copp?r rod, length $18 \mathrm{~cm}$., 
passing through sulphur in a glass cvlinder $5 \mathrm{~cm}$. long, $1.5 \mathrm{~cm}$. diane ${ }^{\circ} \mathrm{r}$, carried a leaf $4.5 \mathrm{~cm}$. long, $1 \mathrm{~mm}$. wide.

\section{TABLE: I.}

Dimensions of plates of air condenser: $35 . \mathrm{sm} .24 \mathrm{~cm}$ : distance apart.

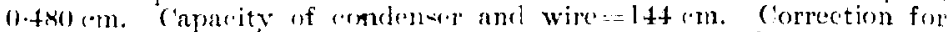

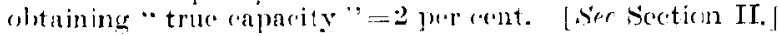

\begin{tabular}{|c|c|c|c|c|}
\hline $\begin{array}{c}\text { Finst } \\
\text { potentian, } \\
\text { l. }\end{array}$ & 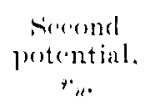 & $\begin{array}{l}\text { No. of } \\
\text { "hargeses } \\
\text { "l. }\end{array}$ & $\begin{array}{c}\text { Capacity } \\
\text { cof } \\
\text { (-lecetroseope. }\end{array}$ & $\begin{array}{c}\text { True capacity } \\
c^{\prime} \text { of } \\
\text { (lectroscope. }\end{array}$ \\
\hline $\begin{array}{l}1000 \text { volts } \\
1000 . \\
1000\end{array}$ & 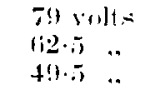 & $\begin{array}{l}\overline{3} \\
10 \\
1 \overline{1}\end{array}$ & 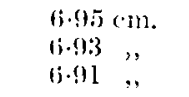 & $\begin{array}{l}7.09 \mathrm{~cm} . \\
7.07 \stackrel{ }{7.05}= \\
=\end{array}$ \\
\hline $\begin{array}{ll}1.30 & . . \\
1.01 & . \\
150 & . .\end{array}$ & $\begin{array}{cc}118 \cdot 0 & . . \\
912 \cdot 5 & . . \\
73 \cdot 0 & . .\end{array}$ & $\begin{array}{l}5 \\
10 \\
15\end{array}$ & $\begin{array}{l}7 \cdot 10, \\
7.13, " \\
7.08, "\end{array}$ & $\begin{array}{l}7 \cdot 24 \quad, \\
7.27 \quad ", \\
7 \cdot 22 \quad,\end{array}$ \\
\hline $2(11)$ & $122 \cdot 0$ & 10 & $7 \cdot 29 \quad$, & $7 \cdot 43 \quad$ \\
\hline 2.511 & $153 \cdot 0$ & 10 & $7 \cdot 24$ & $7 \cdot 38$ \\
\hline $30111 \quad .$. & $18.5 \cdot 1) \quad$. & 10 & $7 \cdot 1: 3 \quad$, & 7.27, \\
\hline
\end{tabular}

2. Emanation Electrowrope.-By C'ook, of Manchester, after a pattern by Sir E. Rutherford. The enanation chamber was crimbrical, of height $14 \mathrm{~cm}$., and was surrounded by a cylindrical chamber of the same diameter and $9.2 \mathrm{~cm}$. in hoight. The rod carring the leaf and penetrating also the lower chamber was provided with a disc of $5 \mathrm{~cm}$. dianeter, opposite which was a similar movable disc, so that the capacity could be varied. The leaf itself was $5 \mathrm{~cm}$. long and $3 \mathrm{~mm}$. wide. The results given in 'Table II. were obtained with the discs at their" maximlim distance apart.

T.BBLE II.

Capacity of condenser and wire $=144 \mathrm{~cm}$. Correction for obtaining true eapacity $=1.5$ per ('ent.

\begin{tabular}{|c|c|c|c|c|}
\hline $\begin{array}{c}\text { First } \\
\text { potential. } \\
V .\end{array}$ & $\begin{array}{c}\text { Second } \\
\text { potential, } \\
c_{n}\end{array}$ & $\begin{array}{c}\text { No. of } \\
\text { charges } \\
n \text {. }\end{array}$ & $\begin{array}{c}\text { Capacity } \\
c \text { of } \\
\text { electroscope. }\end{array}$ & $\begin{array}{c}\text { True capacity } \\
c^{\prime} \text { of } \\
\text { electroscope. }\end{array}$ \\
\hline 240 volts & 202.5 volts & 3 & $8.39 \mathrm{~cm}$ & $8.51 \mathrm{~cm}$. \\
\hline $\begin{array}{l}280 \quad, \\
280 \quad ", \\
280 \quad ", \\
280 \quad "\end{array}$ & $\begin{array}{l}249 \cdot 5, ", \\
235 \cdot 5 \quad ", \\
222 \cdot 5 \quad ", \\
210 \cdot 0 \quad "\end{array}$ & $\begin{array}{l}2 \\
3 \\
4 \\
5\end{array}$ & $\begin{array}{l}8 \cdot 55, ", \\
8 \cdot 55, ", \\
8 \cdot 52, ", \\
8.53,\end{array}$ & $\begin{array}{l}8 \cdot 68,, \\
8 \cdot 68, \\
8.65, \\
8 \cdot 66 \quad,\end{array}$ \\
\hline
\end{tabular}


With the movable disc as near as possible to the fixed disc, the capacity was increased in the ratio of $1.24: 1$.

In this electroscope (kindly lent by $\mathrm{Mr}$. F. H. Glew) the rod (arrying the leaf had a backward slope, so that at about 150 volts the leaf remained very nearly in contact with the rod.]

3. Small Cubical T.ead Electroscope.-This electroscope, of $111 \mathrm{~cm}$. edge, was insulated by a sulphur bead inside the instrument, and charged by means of a metal charger, $C$ (Fig. 3). 'This charger was well insulated by sulphur at $S$, and was of total length $13 \mathrm{~cm}$. The rod carrying the leaf was $6 \mathrm{~cm}$. long and the leaf itself was $4 \mathrm{~cm}$. in length and $1 \mathrm{~mm}$. wide. The joint capacity of leaf system $(=c)$ and charger $\left(=c^{\prime}\right)$ was first determined in the usual way. Then the capacity $\left(c^{\prime}\right)$ of the charger: alone was measured as follows: The condenser, leaf sistem and charger were raised to potential $V$ as given by the

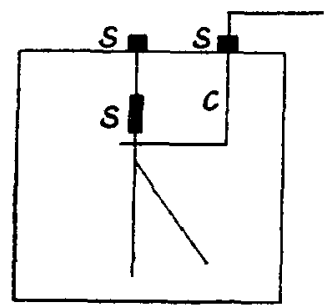

Fic. 2.-Fífectroscope with Ch.IRI: ik $C$.

S S S = Sulphur Insulation.

leffection of the leaf. The condenser was disconnected and lear and charger earthed. The charger was disconnected from the leaf system, charged from condenser and earthed $n$ times. Finally, all three were connected again, and their final potential, $i_{n}$. observed. Under these circumstances it can be calculated that

$$
{ }_{n} v=\frac{C^{n}}{\left(C+c+c^{\prime}\right)\left(C+c^{\prime}\right)^{n-1}} \cdot V,
$$

$n^{\prime} \log \left(C+c^{\prime}\right)=\frac{1}{n-1}\left\{n \log C+\log V-\log \left(C+\overline{c+c^{\prime}}\right)-\log i n^{\prime}\right.$,

trom which $c^{\prime}$, the capacity of the charger alone can be obtained. The results of the deterninations are given in Table III. 
TABLE III.

Correction for obtaining "true capacity" $=\mathbf{2 \cdot 2}$ per cent.

(a) Capasity of Leaf System and "Charger."

\begin{tabular}{|c|c|c|c|c|}
\hline $\begin{array}{c}\text { First } \\
\text { potential, } V .\end{array}$ & $\begin{array}{c}\text { Second } \\
\text { potential } t .\end{array}$ & $\begin{array}{l}\text { No. of } \\
\text { charges. }\end{array}$ & $\begin{array}{c}\text { Capacity of } \\
\text { leaf charger }(c) .\end{array}$ & $\begin{array}{c}\text { True capacity } \\
\left(c^{\prime}\right) .\end{array}$ \\
\hline 300 wolts & $242 \cdot 5$ volts & 10 & $3.80 \mathrm{~cm}$ & $3.17 \mathrm{~cm}$ \\
\hline
\end{tabular}

(b) Capacity of "Charger" alone.

\begin{tabular}{|c|c|c|c|c|}
\hline $\begin{array}{c}\text { First } \\
\text { potential. }\end{array}$ & $\begin{array}{c}\text { Second } \\
\text { potential. }\end{array}$ & $\begin{array}{c}\text { No. of } \\
\text { charges. }\end{array}$ & $\begin{array}{c}\text { Capacity of } \\
\text { "charger." }\end{array}$ & $\begin{array}{c}\text { True capacity } \\
\text { of "charger." }\end{array}$ \\
\hline 300 volts & 256 volts & 10 & $2.22 \mathrm{~cm}$. & $2.27 \mathrm{~cm}$ \\
\hline
\end{tabular}

(c) Hence, true capacity of leaf system alone $=3 \cdot 17-2 \cdot 27=0 \cdot 90 \mathrm{~cm}$.

4. Ionisation Vessel and Gold-leat Electroscope.-.The electroscope examined in Section III. (1) was connected with an "ionisation vessel," $V$ (Fig. 3). This vessel was of cubical form, of edge about $16 \mathrm{~cm}$. A radioactive substance (uranium. oxide) could be placed on a square plate, $A$, of area $64 \mathrm{sq} . \mathrm{cm}$., and a similar plate, $B$, parallel with $A$, was connected to the leat system of the electroscope $E$.

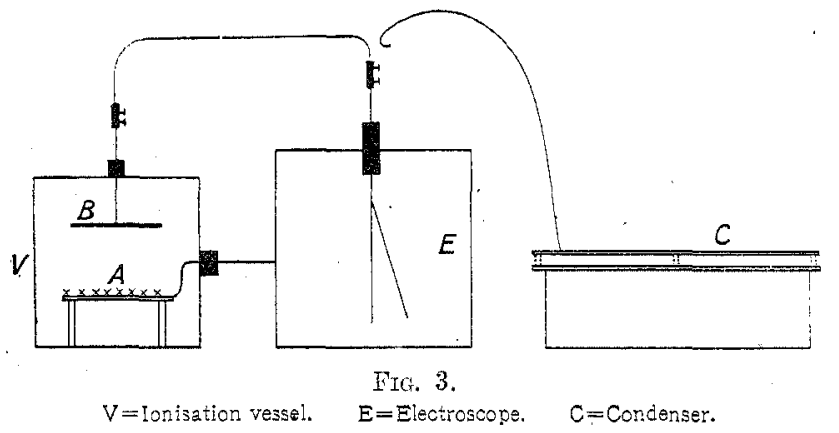

A common method of measuring the capacity of a system including an "ionisation vessal " and electrometer is to observe tho rate of fall of potentia! (as given by the electrometer) due to the ionisation produced between two parallel plates, $A$ and $B,(a)$ when connected with a condenser of known capacity, (b) when the condenser is disconnected.

In orcler to compare this method with the one described in the present Paper the capacity of the system was determined by both methods.

If $C$ is the capacity of the condenser, and $c$ that of the ionisation vessal and electrometer, $T$ and $t$ the times taken for 
a given fall of potential with the condenser $(a)$ connected, $(b)$ lisconnected; then

$$
\frac{C+c}{c}:=\frac{T}{t}, \text { or } c=\frac{C t}{T-t} .
$$

Capreity of Ionisation Vessel and Electroscope.-(1) By measuring rate of fall of potential due to uranium oxide. Potential fell from 300 volts to 211 volts, $(a)$ with condenser of capacity $144 \mathrm{~cm}$., in 50.5 seconds ; (b) without condenser, in is seconds.

\begin{tabular}{|c|c|c|c|}
\hline $\begin{array}{l}\text { First } \\
\text { potential, } \\
V .\end{array}$ & $\begin{array}{c}\text { Second } \\
\text { potential, } \\
v\end{array}$ & $\begin{array}{c}\text { Time with } \\
\text { condenser, } \\
T .\end{array}$ & $\begin{array}{c}\text { Time without } \\
\text { condenser, } \\
t .\end{array}$ \\
\hline 300 volts & 211 volts & 505 secs. & 58.0 secs. \\
\hline
\end{tabular}

The values for the capacity from these observations are $18.68 \mathrm{~cm}$. and $18.31 \mathrm{~cm}$. respectively : or, when correction $(0.9$ per cent.) is made for rarthing wire from condenser, $18.85 \mathrm{~cm}$. and $18.47 \mathrm{~cm}$. respectively.

(2) By the method of this Paper.

\begin{tabular}{|c|c|c|c|c|}
\hline $\begin{array}{c}\text { First } \\
\text { potential, } v .\end{array}$ & $\begin{array}{c}\text { Second } \\
\text { potential, } r\end{array}$ & $\begin{array}{l}\text { No. of } \\
\text { charges. }\end{array}$ & Capacity, c. & $\begin{array}{c}\text { True capacity, } \\
e^{\prime} .\end{array}$ \\
\hline $\begin{array}{l}300 \text { volts } \\
300 \quad, \quad\end{array}$ & $\begin{array}{l}208 \text { volts } \\
185 ",\end{array}$ & $\begin{array}{l}3 \\
4\end{array}$ & $\begin{array}{l}18.70 \mathrm{~cm} . \\
18.50 \%\end{array}$ & $\begin{array}{l}18.87 \mathrm{~cm} . \\
18.67,\end{array}$ \\
\hline
\end{tabular}

Satisfactory agreement is thus obtained in the results given by the two nethods.

\section{V: Discussion of Result:.}

The consistency of the results enumerated in Section III. may appear somewhat surprising to one not acquainted with the possibilities of a nodern gold-leaf electroscope. If proper precautions be taken, a particular experiment can be repeated again and again with practically the same result, and the conditions can be widely varied without much alteration in the final value obtained for the capacity of the electroscope. The divergence of the leaf appears to have very little effect on the caparity of the system as a whole, except, perhaps, when the leaf is nearly in contact with the rod supporting it, in which case the capacity would appear to be slightly lower. This may, however, be due to a decrease in sensitiveness with the leaf in such a position, though Harms* obtained in some cases a similar result. It is worthy of notice that the comparatively 
large capacity of the standard condenser employed-which would be a serious drawback in other methods-presents no difficulty in the method of the present Paper, provided that contact be made between condenser and leaf system a sufficient number of times. With such small capacities as those dealt with here very small ionisation clurrents can be accurately measured. F'or example, in the case of the electroscope of capacity $0.90 \mathrm{~cm}$., the ionisation within the vessel reduced the potential from 300 to 280 volts (corresponding to 20 divisions of the microscope scale) in about an hour. This corresponds to a current of approximately $1.6 \times 10^{-13}$ ampere.

\section{SUMmary.}

The capacities of gold-leaf electroscopes of various patterns have been determined by a method which depends upon obtaining the relation between the divergence of the leaf and thr potential applied to it, and the observation of the fa!l of potential of the leaf system when it shares its charge a convenient number of times with a standard parallel plate air condenser. It is found that the capacity is practically independent of the amount of divergence of the leat, except when this divergence is very small, in which case the capacity becomes slightly lower. Ionisation currents of the order $10^{-13}$ ampere can be arcurately measured by an electroscope or capacity about I cin. For some purposes the gold-lea: electroscope possesses marked advantages over the quadrant electrometer. 'The method employed was found to give satisfactory agreement. with the results ob tained by another method.

\section{ABSTRACT.}

A gold-leaf electroscope is frequently used to compare exceedingly small ionisation currents. For this purpose it is much more sensitive thin a quadrant electrometer. If the capacity of the electroscope is known then the absolute value in amperes of the ionisation current ('an be deduced. A method is described for measuring the capacity of a gold-leaf electroscope, the method depending on sharing the charge of a parallel plate air condenser of measurable capacity as many times as necessary, and deducing the capacity of the electroscope from the observed drop of potential. The nethod gives consistent results when the experimental conditions are widely varied. The amount of deflection of the leaf appears to have little influence on the result.

\section{UISCUSSION.}

Wr. A. CAMPELLL: The consistency of Dr. Barratt's results shows that the modern gold-leaf electroscope is an instrument of precision and justifics the wet of the simple method of divided charge for measuring its capacity. The method, however, tends to make the capacity seom more constant at 
lifferent readings than it really is. When a plate condenser without a guardring is used, tho edge correction can be obtained by Kirchhoff's formula.* But standard variable air condensers marked in micro-microfarads from about 30 up to 200 are now to be had in this country, and form vely con. venient standards of small capacity. The capacities of ordinary electrostatic voltmeters are not very high, that of a 100 -volt Kelvin or Ayrton. Wather instrument being of the order of 70 micro-microfarads. Their large variation with the reading shows that, unlike the gold-leaf type, these instruments have very little ineffective capacity. For the measurement of small capacities the Carey Foster method seems the most convenient, and it gives the power factor at the same time. With 20 volts on the condenser at a frequency of $800 \approx$ por second, a capacity of 5 micro-microfarads can be measured with an accuracy of about 1 per cent. It is a pity that the author gives his results in mixed units, the voltages being in electromagnetic units (volts) and the capacities in electrostatic units; this can only lead to confusion. 'The practical system of volts, amperes, coulombs, farads, \&c., is sufficiont for all actuol measurements.

Capt. C. E. S. PHILLIPS observed that the experiments in which the capacity of a system containing an ionisation ressel was compared by two methods showed that the capacity of a condenser with ionised air between the plates was not different from its capacity with unionised air as dielectric.

Prof. G. W. O. Howe suggested that the reason the capacity of the electroscope was uninfluenced by the vicinity of the charged wire from the condenser was that the capacity of the wire was small; it had nothing to do with the lines of force of the condenser.

Dr. BARRATT : The edge effect in the condenser used was very small, as the plates were each of area $840 \mathrm{sq}$. cm. and only $0.48 \mathrm{~cm}$. apart. This was, however, allowed for by comparison with a guard-ring air condenser. The capacity of most gold-leaf electroscopes is of the order of 1 micro-microfaradi.c., only $1 / 50$ to $1 / 100$ of that mentioned by Mr. Campbell. The air condensers which Mr. Campbell describes are of capacity 50 to 200 times that to be measured, which would be a great objection in other methods than that in the Paper. Carey Foster's method appears to become less accurate as the capacity to be measured approaches those dealt with in the present research. The apparatus, again, is more costly and less simple. The mixing of the units was due to the fact that the measurements were simply put down in the particular system of units employed in each measurement. Prof. Howe's alternative explanation of the want of effect of the charged wire a ppeared to be only a nother way of expressing the same fact. In the case of a charged sphere in contact with the electroscope the capacity of the latter is influenced by the lines of force radiating from the sphere, while in the case of the condenser the connecting wire is of comparativaly small capacity, and is connected, therefore, with fewer lines of force.

$$
\text { * Berlin "Akard. Monatsberichte," p. 144, } 1877 .
$$

